DOI: 10.4322/978-65-89910-16-9-05

\title{
A IMPORTÂNCIA DA CONTABILIDADE GERENCIAL PARA O ADMNISTRADOR: estudo de caso no escritório contábil Wbarros Consultoria Contábil
}

\author{
Aldenira Alves 22 \\ Gilcimar Guimarães Berredo 23 \\ Ilton Cley Farias ${ }^{24}$ \\ Jaqueline Pimentel ${ }^{25}$ \\ Walber Vieira Gomes ${ }^{26}$
}

\footnotetext{
${ }^{22}$ Discente do curso de Administração da Faculdade Edufor (in memoriam). E-mail: contato@edufor.edu.br

${ }^{23}$ Discente do curso de Administração da Faculdade Edufor. E-mail: gilcimar.berredo@outlook.com

24 Discente do curso de Administração da Faculdade Edufor. E-mail: Iltonfarias123456@gmail.com

${ }^{25}$ Docente da Faculdade Edufor. E-mail: jaqueline.pimentel@edufor.edu.br 26 Discente do curso de Administração da Faculdade Edufor. E-mail: wgcvieira@gmail.com
} 
A IMPORTÂNCIA DA CONTABILIDADE GERENCIAL PARA O ADMNISTRADOR: estudo de caso no Escritório contábil Wbarros Consultoria Contábil

\section{RESUMO}

O presente estudo visa descrever a importância da contabilidade gerencial, sua função na tomada de decisão, quais são as ferramentas mais usadas e em que podem ser aplicados os relatórios gerados pelas informações contidas nos sistemas de gestão. O trabalho apresenta pesquisa bibliográfica descritiva para embasamento científico dos conteúdos abordados, também conta com pesquisa exploratória por meio de entrevista. Todo conteúdo abordado resulta na afirmação de que a contabilidade gerencial é uma ferramenta indispensável para o desenvolvimento e sobrevivência de uma organização não importando seu ramo ou porte.

Palavras-chave: Contabilidade gerencial. Tomada de decisão. Sistema de gestão. Administração.

\section{ABSTRACT}

The present study aims to describe the importance of management accounting, its role in decision making, what are the most used tools and in which reports generated by information contained in management systems can be applied. The work presents descriptive bibliographic research for scientific basis of the contents covered, also includes exploratory research through interviews. All content covered results in the statement that management accounting is an indispensable tool for the development and survival of an organization, regardless of its branch or size.

Keywords: Management accounting. Decision making. Management system. Management. 
A IMPORTÂNCIA DA CONTABILIDADE GERENCIAL PARA O ADMNISTRADOR: estudo de caso no Escritório contábil Wbarros Consultoria Contábil

\section{INTRODUÇÃO}

O aumento das atividades comerciais e de produção, especialmente no continente europeu, reflexo da Revolução Industrial no século XVIII, impulsionou a contabilidade. A alta demanda nos serviços contábeis corroborou com o surgimento dos contadores públicos.

Nesse período, o crescimento das atividades contábeis é enorme, abrangendo as áreas da contabilidade de custos e a auditoria. O crescimento de empresas e indústrias e o aumento da sua complexidade fazem as demandas aparecerem. A partir de então, passa a existir a necessidade de usar a contabilidade para diferenciar capital, lucro e rendimento. Bem como declarar - lucro, a regulação do cálculo da despesa decorrente e outras informações de cunho financeiro e contábil.

Com o crescimento no número de novas empresas, tornou-se necessário saber se o consumo de recursos na produção de bens ou serviços estava dando retorno. Dessa forma, surge à necessidade de precificar os valores de processo de conversão das matérias e da mão-de-obra 
A IMPORTÂNCIA DA CONTABILIDADE GERENCIAL PARA O ADMNISTRADOR: estudo de caso no Escritório contábil Wbarros Consultoria Contábil

em produtos, e verificar seu resultado para a organização. Isso veio acontecer logo depois da revolução industrial.

As primeiras organizações a trabalharem 0 desenvolvimento da contabilidade gerencial foram as comerciais que trabalhavam com tecelagem de algodão nos Estados Unidos.

Mesmo hoje em dia muitos empreendedores ainda não utilizam métodos ou sistema que forneçam informações que auxiliem na sobrevivência, crescimento e desenvolvimento saudável de suas organizações; por falta de procurarem conhecer as ferramentas que existem para auxiliar em seus processos contábeis ou mesmo um contador. Isso acaba prejudicando na coleta de informações geradas pela contabilidade gerencial, que é de grande importância na tomada de decisão, monitoramento de resultados e aplicação segura de recursos.

Tendo isso em vista, o presente trabalho busca informar sobre a os benefícios gerados pela contabilidade gerencial, munir os gestores com ferramentas primordiais para a tomada de decisões e que são essenciais para a sobrevivência de qualquer organização. Busca ainda 
A IMPORTÂNCIA DA CONTABILIDADE GERENCIAL PARA O ADMNISTRADOR: estudo de caso no Escritório contábil Wbarros Consultoria Contábil

demonstrar por meio de pesquisa bibliográfica do tipo descritiva e resultados da aplicação de questionário e entrevista em empresa de contabilidade dar mais embasamento, confiança e veracidade das informações fornecidas pela contabilidade gerencial como sendo seguras e eficazes na tomada de decisão. O conteúdo abordado visa também mostrar que a contabilidade não tem somente a função fiscal, mas, também é uma forte auxiliadora no crescimento de uma organização e tem a função consultiva.

\section{REFERENCIAL TEÓRIO}

Com o avanço da tecnologia e o mercado em expansão, a Contabilidade passou a ganhar mais importância na gestão das empresas, já que o gestor se preocupou com a saúde financeira de seu negócio procurando saber quais seriam suas fraquezas e seus pontos fortes. Com a chegada da Contabilidade o administrador viu uma ferramenta extremamente importante para a tomada de decisão para melhoria nos 
A IMPORTÂNCIA DA CONTABILIDADE GERENCIAL PARA O ADMNISTRADOR: estudo de caso no Escritório contábil Wbarros Consultoria Contábil

processos gerados na organização vinda a nascer, a Contabilidade Gerencial.

\subsection{Contabilidade Gerencial}

A contabilidade gerencial, também conhecida como contabilidade de gestão, é a área da contabilidade onde são geradas informações importantes para a tomada de decisões. Ela é indispensável e envolve vários procedimentos e técnicas contábeis, a exemplo da contabilidade de custos e financeira, além da análise de demonstrações contábeis. Esse conjunto auxilia a contabilidade gerencial a gerar relatórios para a tomada de decisões.

Padoveze (2012) afirma que a contabilidade gerencial reúne todos os demais mecanismos da contabilidade que se integram à contabilidade financeira para torna efetiva à informação contábil dentro das empresas em todos os processos da gestão. Sendo assim o profissional responsável por este ramo contábil deverá estar apto para gerenciar, recolher, atribuir e adapta às necessidades dos gestores e transmitir de forma precisa e clara as informações geradas. 
A IMPORTÂNCIA DA CONTABILIDADE GERENCIAL PARA O ADMNISTRADOR: estudo de caso no Escritório contábil Wbarros Consultoria Contábil

Para Padoveze (2012), essas informações precisam ser relatadas e devem estar em perfeita conformidade a cada tomada de decisão e para todos os que irão usufruir delas. Dessa forma, em todos os níveis, essa ciência deve ser fornecedora de informações importantes e decisivas, trabalhando com uma consulta ativa nos processos de planejamento e controle de tudo na organização.

\subsection{Tomada de Decisão}

A tomada de decisão é o método pelo qual se escolhe o caminho a ser percorrido para o alcance de um objetivo ou resolução de um problema, devendo ser o método selecionador das melhores alternativas possíveis.

Essas alternativas devem ser baseadas em fatos, dados, informações e conhecimentos técnicos que auxiliem na elaboração e escolhas das opções mais assertivas.

Uma decisão é desenvolvimento de um raciocínio. É uma escolha entre alternativas. Raramente é uma opção entre o certo e o errado. Na melhor das hipóteses é uma escolha entre o "quase certo" e o "provavelmente errado" - porém, muito mais frequentemente, é uma escolha entre dois cursos de ação, não sendo nenhum deles mais certo do que o outro (DRUKER, 2002, p. 119). 
A IMPORTÂNCIA DA CONTABILIDADE GERENCIAL PARA O ADMNISTRADOR: estudo de caso no Escritório contábil Wbarros Consultoria Contábil

Portanto, raramente terão direcionamentos certos ou errados por que a decisão é elaborada a partir do raciocínio, ou seja, normalmente vai se alternar entre bem provável ou mais ou menos errado.

Wright (2011) afirma que as decisões estratégicas são orientadas para o futuro, com ramificações em longo prazo. Dessa forma, é necessário firmeza de propósito e visão de futuro para tomada de decisão estratégica.

De acordo com Shimizu (2006) apud Cruz (2016), uma empresa precisa estar alinhada e bem ordenada de modo formal. Os dados coletados devem ser claros, tendo em vista que os problemas que demandam decisões são amplos e complexos, envolvem riscos e incertezas e envolvem a opinião e a participação de muitas pessoas.

Compreende-se que os gestores têm a responsabilidade de conhecer as ferramentas necessárias para uma boa gestão junto à contabilidade gerencial. Na tomada de decisão é importante que seja levado em consideração as informações coletadas para o que se pretender fazer. Isso é necessário para que a empresa consiga avançar dentro do mercado instável e 
competitivo. A contabilidade é imprescindível para os resultados positivos da empresa.

O autor deixa claro que as decisões tomadas pelos gestores devem ser estruturadas, fundamentadas. Para tanto é necessário ter informações relevantes para uma decisão assertiva.

\section{O QUE É A CONTABILIDADE GERENCIAL E SUA FUNÇÃO PARA OS GESTORES DAS EMPRESAS}

A Contabilidade é uma ciência social diligente que tem como referencial próprio de estudo o Patrimônio das entidades, tendo como grande meta a propagação financeira inteligível aos usuários para a tomada de decisões.

Segundo Garçom, Noreen e Brewer (2013), as informações fornecidas para os gerentes para o uso na organização são geradas pela contabilidade gerencial. Distinto da contabilidade financeira cuja finalidade é escorar à necessidade de quem está fora da organização (usuários externos), a contabilidade gerencial vem inteirar as necessidades dos gerentes dentro da organização 
A IMPORTÂNCIA DA CONTABILIDADE GERENCIAL PARA O ADMNISTRADOR: estudo de caso no Escritório contábil Wbarros Consultoria Contábil

(usuários Internos). A contabilidade gerencial ressalta as decisões que afetam o futuro, a magnitude, o fazer as coisas atendendo o prazo estabelecido e o cumprimento no nível do seguimento.

A contabilidade gerencial faz uso de todas as informações contábeis úteis para uma boa gestão dentro da empresa atuando diferente da contabilidade financeira, que se limita a práticas contábeis decorrentes dos princípios fundamentais da contabilidade. Portanto, a contabilidade gerencial vai além desses preceitos e agrega conceitos econômicos e financeiros necessários para a otimização da coleta de dados que serão importantes para as tomadas de decisões assertivas na empresa.

É o método utilizado para a coleta de dados com o intuito de passar essas informações financeiras de forma clara, pois serão usadas pela administração para 0 planejamento, avaliação e controle dentro de uma organização e assegurar o uso apropriado e responsável de seus recursos (HORNGREN, SUNDEM e STRATTON, 2004, p. 4; WARREN, REEVE e FESS, 2001, p. 2; IUDíCIBUS, 1998, p. 21; ATKINSON, et al, 2000, p. 67).

Dessa forma, conclui-se que a Contabilidade Gerencial é equivalente à informações contábeis geradas 
A IMPORTÂNCIA DA CONTABILIDADE GERENCIAL PARA O ADMNISTRADOR: estudo de caso no Escritório contábil Wbarros Consultoria Contábil

aos responsáveis pela gestão das organizações de forma a assegurar a melhor usabilidade dos recursos em geral, auxiliando na sobrevivência do negócio.

\subsection{Principais ferramentas da contabilidade gerencial e sua importância na tomada de decisões}

Utilizados como ferramentas auxiliares no processo de tomada de decisões nas empresas os relatórios contábeis gerenciais são imprescindíveis para os administradores. Os relatórios são: o Balanço Patrimonial, Demonstração de Resultado do Exercício - (DRE), as Demonstrações do Fluxo de Caixa e o Orçamento.

Para Singer e De Cesaro (2003), são também conhecidos como demonstrativos contábeis gerenciais os dispositivos utilizados para auxiliar e apoiar o processo decisório. Seu levantamento não é obrigatório, porém suas averiguações são adequadas para fortalecer os demais relatórios e respaldar os objetivos da organização.

Para Henrique (2008), os instrumentos da contabilidade gerencial são dispositivos para tomada de decisões gerenciais, a Contabilidade tem como finalidade principal oferecer informações financeiras e patrimoniais 
das entidades, de maneira pertinente, confiável, segura e de qualidade. o Balanço Patrimonial, Demonstração do Resultado do Exercício - (DRE) e a Demonstração do Fluxo de Caixa.

Para Padoveze (2010, p. 517) "o orçamento é o material de controle por primazia de todo o dinamismo operacional da empresa, pois envolve todos os setores". Esses relatórios são registros que podem ser usados para acompanhar os resultados e a situação atual da organização. Trazendo consigo a análise dos dados obtidos, inúmeros ganhos quantitativos e qualitativos que estão à frente da visualização e controle do crescimento da empresa e do número de produção.

\subsubsection{Balanço Patrimonial}

Tem como função disponibilizar informações aos gestores e usuários externos e internos das organizações os deixando a par da situação da organização, mostra uma visão estratégica da mesma e auxilia no alcance de melhores e maiores resultados, pois trabalha munindo os gestores para melhor tomada de decisões. Dessa forma, 
A IMPORTÂNCIA DA CONTABILIDADE GERENCIAL PARA O ADMNISTRADOR: estudo de caso no Escritório contábil Wbarros Consultoria Contábil

é mais fácil estar ciente das limitações e oportunidades atuais e futuras da empresa!

Para Roppelli e Nikbakht (2002) os valores que aparecem no balanço patrimonial da empresa representam 0 valor histórico do total dos ativos disponíveis para gerar vendas e lucros. Dessa forma para que a empresa consiga trabalhar seus recursos de formas assertiva e perpetuar seu crescimento, os gestores devem ter em mente que os recursos que ela tem em sua totalidade e usabilidades são conhecidas por meio das contas que compõem o balanço patrimonial.

3.1.2 Demonstração de Resultado do Exercício - (DRE)

A Demonstração de Resultado do Exercício - (DRE) estrutura a posição patrimonial e financeira de uma empresa, além de demonstrar o desempenho da mesma. Tem como finalidade fornecer informações que sejam usuais aos gestores e tomadores de decisões econômicas. A mesma ainda disponibiliza os resultados da atuação da administração, deixa transparente os deveres e responsabilidades em visão dos recursos confiados. 
A IMPORTÂNCIA DA CONTABILIDADE GERENCIAL PARA O ADMNISTRADOR: estudo de caso no Escritório contábil Wbarros Consultoria Contábil

As Demonstrações dos Resultados do Exercício - DRE comprova qual o rendimento gerado, os dispêndios e despesas da época, bem como o lucro (ou prejuízo) da operação. Tão logo seja disponibilizado 0 demonstrativo pela contabilidade, devemos fazer um estudo comparativo e criterioso das informações alcançadas de modo a constatar se o resultado apresentado está dentro daquilo que foi esperado pela empresa, ou se a lucratividade do negócio ficou abaixo ou acima da expectativa (BOCH, 2009, p. 11).

Sendo assim, por meio da DRE é possível saber

como anda a situação financeira da empresa e se as metas planejadas foram alcançadas. Ainda a mesma ferramenta traz informações que auxiliam no planejamento posterior.

\subsubsection{Demonstração do Fluxo de Caixa}

Dispositivo que demonstra por meios de resultados de onde saiu o capital que se encontra no caixa da empresa e onde foi aplicado, ou seja, entradas e saídas. Nele é possível saber os valores operacionais e a transportar.

(...) a Demonstração de Fluxo de Caixa (DFC) indica a procedência de todo o capital que entrou no Caixa, bem como a aplicação de todo o capital que saiu do 
A IMPORTÂNCIA DA CONTABILIDADE GERENCIAL PARA O ADMNISTRADOR: estudo de caso no Escritório contábil Wbarros Consultoria Contábil

Caixa em determinada época, e, ainda o Resultado do Fluxo Financeiro. Essa demonstração tem a característica de tornar claras as transações que efetivamente movimentam o caixa. O que poderia ser uma característica questionável. $O$ registro de movimentações de caixa é muito enérgico; a demonstração de fluxo de caixa, tal quais as demais demonstrações, trata da coleta e análise, ou seja, reflete um determinado momento ou, mais propriamente dizendo, um determinado saldo disponível e comedido. Portanto, não devemos analisar o fluxo de caixa dessa forma, estática, verticalmente como são apresentados, uma vez que essa não é a realidade das empresas (MARION, 1998, p. 380).

Os relatórios de fluxo de caixa demonstram o ponto de partida das entradas no caixa e a aplicação do capital, auxiliam na elaboração do plano financeiro para compromissos futuros. Além de dar assistência no desenvolvimento de estratégias de vendas, planos de investimentos e ações de decisão. Por meio do fluxo de caixa é possível checar os pagamentos em determinados períodos, os fluxos de entradas e médias de valores. Tudo isso contribui para a análise de futuros investimentos e melhores prazos.

\subsubsection{Orçamento}


A IMPORTÂNCIA DA CONTABILIDADE GERENCIAL PARA O ADMNISTRADOR: estudo de caso no Escritório contábil Wbarros Consultoria Contábil

O orçamento empresarial, segundo Hanse e Mowen (1996), é um programa financeiro amplo para a organização e traz vários benefícios: solidez dos gestores ao elaborar plano, informações no processo de decisão, medida de peso nos recursos a serem utilizados, em seguida, pode ser utilizado na avaliação de desempenho e facilita a comunicação.

$\mathrm{Na}$ visão dos conceitos de Leite et al. (2008, p. 58) "orçamento é a união entre planejamento e controle". A ideia do orçamento empresarial deve ser executada, nenhuma empresa lucrou somente em fazer planos. Para Tung (1976) o controle orçamentário é um dispositivo que auxiliam na previsão do comportamento da organização influenciando diretamente na boa administração dos recursos.

Um orçamento é um plano que vai servir também para o futuro, que em geral é expresso em quantidades formais. A união de diversos orçamentos forma um plano incorporado de negócios, conhecido como orçamento mestre. O orçamento mestre é um dispositivo gerencial que junto com os orçamentos são planejados os passos para o objetivo, executando todos os processos 
A IMPORTÂNCIA DA CONTABILIDADE GERENCIAL PARA O ADMNISTRADOR: estudo de caso no Escritório contábil Wbarros Consultoria Contábil

necessários para alcance das metas. O orçamento também comunica os planos da gerência a toda a organização, aloca recursos e coordena atividades.

\section{A IMPORTÂNCIA DO CONTADOR GERENCIAL PARA A GESTÃO DE UMA EMPRESA}

Para ludícibus (1986),o contador gerencial, precisa ter uma formação elevada sobre as técnicas e tudo que está inserido na área gerencial da contabilidade, pelo menos em relação aos objetivos e resultados que podem ser alcançados com métodos de análise. Ele é responsável em transformar números em resultados para uma boa tomada de decisão, ou seja, alguém que deve participar das atividades administrativas de seus clientes, auxiliando para que esses possam dedicar-se exclusivamente a parte administrativa.

O profissional contábil é indispensável para um bom desempenho da empresa. O contador auxilia no planejamento de estratégias e metas a serem alcançadas. Além disso, pode fornecer dados à empresa sobre sua produtividade na área de vendas ou ainda na fabricação, 
por meio dos dados obtidos do fluxo. O profissional contábil ainda apresenta a visão de futuro do empreendimento ao empreendedor com base nas análises contábeis gerenciais. Com isso, o gestor terá fundamento para a tomada de decisões, tais como novas metas e estratégias, demissões ou contratações, treinamento, dentre outras iniciativas.

\section{A IMPORTÂNCIA DOS DADOS FORNECIDOS PELOS SISTEMAS DE INFOR-MAÇÕES CONTÁBEIS PARA UMA ORGANIZAÇÃO}

Em um mundo volátil, de incertezas e globalizado a necessidade de se ter informações contábeis é essencial para a sobrevivência de uma empresa no contexto atual que se vivemos. Elas vão contribuir significativamente para tomada de decisões mais assertivas. Pois os dados são primordiais para verificar a real situação de uma empresa e pode assim trazer excelentes resultados.

O administrador, no uso das suas atribuições, necessita de um sistema de informação que vai auxiliá-lo nos processos decisórios através dos dados nele contido. 
A IMPORTÂNCIA DA CONTABILIDADE GERENCIAL PARA O ADMNISTRADOR: estudo de caso no Escritório contábil Wbarros Consultoria Contábil

Em razão disso, Schmidt, Santos e Pinheiro (2002), diz que o sistema de informação da definição como um conjunto de procedimentos estruturados, planejados e organizados que, uma vez executados, produzem informações para suporte ao processo de tomada de decisão.

Para tanto, o administrador precisa estar capacitado para interpretar as informações contábeis dos relatórios, bem como escrituração, análises de balanço patrimonial e demonstrações do resultado do exercício. Com a interpretação correta desses dados, o gestor terá embasamento para a tomada de decisão mais assertiva, e, consequentemente, melhores resultados.

A contabilidade é uma importante ferramenta de gestão. Ela permite análise e monitoramento dos dados. Conhecer o fluxo financeiro e patrimonial da empresa é vital para o negócio; especialmente, no momento atual, com as empresas cada vez mais competitivas e em constante evolução.

Diante desse cenário, os sistemas de informações contábeis são fundamentais para a empresa, pois fornecem dados sobre a situação financeira e contábil, 
A IMPORTÂNCIA DA CONTABILIDADE GERENCIAL PARA O ADMNISTRADOR: estudo de caso no Escritório contábil Wbarros Consultoria Contábil

que contribuem para a elaboração do planejamento estratégico, focando no futuro da empresa.

O principal objetivo do sistema é realizar a previsão de receitas e de despesas, selecionar as melhores fontes e o uso dos recursos a curto e longo prazo, fazendo a análise de investimentos e da situação financeira da empresa (SOUZA, 2008, p. 3).

Existem dispositivos de informações mais específicas que poucas empresas tem se utilizado delas com a finalidade de focar em um nível mais objetivo, é o caso do sistema de informação executiva (SIE). Voltada para o nível estratégico da empresa ela tem por finalidade auxiliar o gestor a fazer a análise, e as comparações mais detalhadas e mostrar fatores de oportunidades como de ameaças, contribuindo para ações antecipadas.

São especialmente projetados para ajudar o executivo a obter insights e rastrear os fatores críticos de sucesso. O objetivo de um sistema de informação executiva é ajudar o decisor na assimilação rápida de informações e na identificação de problemas e oportunidades, não é uma ajuda na análise de problemas ou na sua resolução (MARTIN, 1990, apud LIMA. 1998, p. 39).

Com a utilização do sistema de informação executiva (SIE), possibilitou aos executivos escolherem ações mais ágeis em função da sua estrutura, pois são fáceis de usar, 
suas informações são sempre atuais, podem selecionar e verificar dados importantes de forma eficaz. Porém este sistema exige um alto investimento, sendo assim, tornase necessário quantificar para analisar a possibilidade do retorno. As informações contábeis são cruciais para o bom desempenho de toda empresa, pois revela o diagnóstico em um dado momento sobre a saúde da organização e as ferramentas de informações contábeis podem prover soluções para tomada de medidas necessárias e oportunas para correção de possíveis falhas e antecipação de medidas com o foco na lucratividade com equilíbrio.

\section{METODOLOGIA}

A metodologia usada no presente trabalho foi a pesquisa exploratória com revisão bibliográfica, aplicação de questionário à um escritório contábil entrevistado. Para melhor compreensão do conteúdo abordado e para ter embasamento científico foi utilizada a pesquisa bibliográficas sendo as matérias utilizadas: fatos históricos, livros de contabilidade gerencial e gestão de 
A IMPORTÂNCIA DA CONTABILIDADE GERENCIAL PARA O ADMNISTRADOR: estudo de caso no Escritório contábil Wbarros Consultoria Contábil

negócios, sites da internet, periódicos, publicações de revistas, monografias, teses e artigos acadêmicos. Para melhor obtenção de informações junto ao responsável pela empresa foi elaborado um estudo de caso através de um questionário com pergunta abertas e fechadas com o intuito de ter o ponto de vista de um profissional contábil.

É também um estudo de caso. Segundo Gil (2007) conhecido como um estudo que se preocupa em investigar as questões que fazem referência ao ser humano, a empresa, ao grupo ou a tudo que está nesse contexto e possa ser utilizado nas diversas áreas do conhecimento.

Em um cenário de constantes mudanças econômicas, as dificuldades para sobreviver têm sido cada vez mais desafiadoras dentro desse globo. Com tantas obrigações para realizar em um mercado cada vez mais exigente, se faz necessário relatórios de contabilidade gerencial mais eficientes para que se consiga tomar decisões nesse mercado que está sempre competitivo, a contabilidade teve que se atualizar para suprir as necessidades das grandes e pequenas empresas. 
A IMPORTÂNCIA DA CONTABILIDADE GERENCIAL PARA O ADMNISTRADOR: estudo de caso no Escritório contábil Wbarros Consultoria Contábil

O estudo de caso foi através de um questionário aplicado em escritório contábil com o objetivo de coletar informações sobre a contabilidade gerencial e sua utilização, a fim de ser possível trabalhar melhor a contabilidade gerencial nas organizações atendendo às necessidades dos gestores na tomada de decisão.

O entrevistado respondeu às perguntas contidas no questionário de maneira online e síncrona. Suas respostas foram analisadas juntamente com o conteúdo abordado neste artigo, por meio dessa análise foi possível ter algumas afirmações.

Foi entrevistado ao senhor Wanderson Barros, proprietário da Wbarros Consultoria Contábil, localizada na Rua Retiro de Natal N.94, Jd. Eldorado, Bairro Turú, em São Luís/MA.

A empresa teve início em setembro de 2018, com apenas três clientes fixos. Mas, hoje já conta com 110 clientes. Sendo uma empresa Eireli, empresa Individual de Responsabilidade Limitada.

A empresa possui quatros funcionários, sendo dois no departamento de pessoal, um no departamento fiscal e uma secretaria. Eles prestam acessória contábil para o 
A IMPORTÂNCIA DA CONTABILIDADE GERENCIAL PARA O ADMNISTRADOR: estudo de caso no Escritório contábil Wbarros Consultoria Contábil

ramo de empresas privadas, e não tem parcerias com outros escritórios.

\subsection{Questionário}

A busca da coleta de dados junto a empresa Wbarros Consultoria Contábil foi de muita valia para assegurar que a contabilidade gerencial é muito importante para o administrador na tomada de decisão, pois ao questionarmos a importância, o diretor proprietário asseverou que as informações são úteis e tem papel fundamental. Depois ele descreveu a importância da contabilidade na vida das empresas, assegurando que os dados contábeis são fundamentais para a elaboração do planejamento da empresa. Tratou-se ainda dentro da pesquisa sobre as ferramentas utilizadas pela contabilidade gerencial e foi citado: a gestão de documentos, escrituração contábil, sistema de cobrança, gestão financeira, auditoria, balanço patrimonial e controle de custos. ludicibus (1995, pag. 91) diz:

A contabilidade gerencial no contexto mais amplo está voltada única e exclusivamente para a gestão da empresa, procurando supri-la com informações que se encaixem 
A IMPORTÂNCIA DA CONTABILIDADE GERENCIAL PARA O ADMNISTRADOR: estudo de caso no Escritório contábil Wbarros Consultoria Contábil

de maneira válida e efetiva no modelo decisório do Administrador.

Portanto a contabilidade gerencial com suas ferramentas é analítica e garante ao administrador informações assertivas que sustentarão o processo decisório.

Foi inquirido ainda quais os principais objetivos da contabilidade gerencial no processo de gestão, o nosso respondente disse que é minimizar erros e eliminar fraudes e ter informações suficientes para traçar estratégias para a empresa.

Em outra questão, utilizando escala de 1 a 4 foi questionado qual seria a média de conhecimento do cliente acerca da interpretação do relatório pelos seus clientes, segundo a pesquisa o conhecimento é pouco, daí a necessidade de uma empresa de consultoria. Acrescentou ainda que os clientes sempre utilizam as informações gerenciais, em forma de relatório para tomada de decisões.

Foi declarado ainda pelo respondente, que geralmente os clientes da Wbarros Consultoria Contábil buscam a empresa para resolver questões burocráticas e fiscais. 
A IMPORTÂNCIA DA CONTABILIDADE GERENCIAL PARA O ADMNISTRADOR: estudo de caso no Escritório contábil Wbarros Consultoria Contábil

\section{RESULTADOS}

Com uma competitividade cada vez mais crescente é de suma importância que as empresas entendam a necessidade de se saber tomar decisões de forma eficiente e eficaz com o intuito de preservar o bom andamento da empresa e assegurar que suas informações contábeis serão usadas eficientemente. $O$ que propusemos foi alcançado por meio de uma pesquisa bibliográfica e através do estudo de caso.

Através do questionário conseguimos verificar como a Contabilidade Gerencial é um grande instrumento que auxilia a administração na tomada de decisões e planejamento das organizações. A cada dia que passa, tem sido cada vez mais difícil gerenciar e planejar dentro das empresas de forma otimizada. Os dados contábeis ajudam a empresa a preparar o orçamento e a previsão para o período futuro. As tendências de negócios são projetadas com base em dados passados produzidas pelo sistema contábil. 
A IMPORTÂNCIA DA CONTABILIDADE GERENCIAL PARA O ADMNISTRADOR: estudo de caso no Escritório contábil Wbarros Consultoria Contábil

As informações contábeis ajudam a ter conhecimento de tudo que se passa na Empresa, fazer Relatórios como o balanço patrimonial e o Demonstrativo de Resultados (DRE) trazem informações seguras. Essas informações colaboram não só para a administração como também para a tomada de decisão.

Torna-se importante que a área e suas funções passem a ser vistas como estratégicas. A exigência da participação da área contábil e de controle interno na averiguação de erros e fraudes que devem compor responsabilidade primária e estruturação básica.

O pesquisado destaca que dentre os clientes que possuem, poucos pedem relatórios interpretados para que eles consigam toma uma decisão importante na empresa. A maioria dos clientes busca um contador hoje por questões fiscais e como forma de simplificar questões burocráticas.

A contabilidade gerencial faz a verificação dos relatórios para poder coletar os dados e as informações que serão necessárias para auxiliar as empresas na tomada de decisão. Por meio de um exame minucioso a contabilidade gerencial poderá averiguar quais são os 
problemas e as falhas em seus processos. Ao mesmo tempo em que a administração procura formas para resolver as dificuldades e os problemas decorrentes nos processos. Para poder ajudar as empresas a saberem se preparar para a tomada de decisão antes dos fatores adversos, deixando claros, as informações e os dados coletados para as tomadas de decisões. Segundo Padoveze (2012, p. 28):

[...] a contabilidade tem um papel muito importante, pois ela faz o controle e também apurar as informações em todas as etapas necessárias para os processos determinantes [...].

Ela faz o processo de análise periódica para ajuda na tomada de decisão identificando e analisando todos as situações decorrentes para poder eliminá-los, acompanhando os modelos já estabelecidos nos processos de planejamento e controle, com essas informações levantadas, se consiga tomar uma decisão com condições prováveis.

\section{CONCLUSÃO}


A IMPORTÂNCIA DA CONTABILIDADE GERENCIAL PARA O ADMNISTRADOR: estudo de caso no Escritório contábil Wbarros Consultoria Contábil

Ao longo do artigo fica clara a importância da contabilidade geral, sua relevância como consultiva na tomada de decisão, sua função de prover informações seguras e de fácil interpretação aos gestores e aos usuários internos que necessitem delas.

Constatou-se que a empresa WBarros Consultoria Contábil, através do proprietário Wanderson Barros, utiliza a contabilidade gerencial como ferramenta para auxiliar seus clientes para a tomada de decisão.

Ficou claro ainda que a empresa tem como foco ajudar seus clientes no que diz respeito aos processos de gestão que elas desenvolvem, e com isso procura dar suporte para que elas consigam obter resultados; sendo ações que ajudem a empresa a não cometer erros, traçando assim estratégias e enviando relatórios para auxiliar essas empresas em cada tomada de decisão.

Concluiu-se, que a importância da contabilidade gerencial não é só para tomada de decisões, mas também como instrumento que auxilia o desenvolvimento do planejamento estratégico da empresa tornando-a mais competitiva 
Fazendo relatórios como o Balanço Patrimonial e o Demonstrativo de Resultados (DRE), trazendo informações seguras que vão colaborar não só à administração como na tomada de decisão.

Ressaltamos aqui a importância da contabilidade gerencial para a gestão estratégica, necessária para que se tenha o controle adequado em todas as fases dos processos dentro da empresa, sendo de grande serventia no planejamento empresarial, pois ao se verificar as necessidades da empresa, se permite estabelecer os padrões para solucioná-las. 
A IMPORTÂNCIA DA CONTABILIDADE GERENCIAL PARA O ADMNISTRADOR: estudo de caso no Escritório contábil Wbarros Consultoria Contábil

\section{REFERÊNCIAS}

$\mathrm{BOCH}$, Bruna. Contabilidade gerencial como ferramenta para gestão de micro empresas e pequenas empresas. Lages: Centro Universitário Unifacvest, 2009.

CRUZ, Felipe. Tomada de decisão: o que os autores dizem sobre o tema, 2016. Disponível em: $<$ https://pt.linkedin.com/pulse/tomada-dedecis\%C3\%A3o-o-que-os-autores-dizem-sobre-temacruz-dsc-pmp>. Acesso em: 05 de maio de 2021. DIAS, E. O contador gerencial. Boletim CRC SP, São Paulo, p. 12-13, ago 2006.

DRUKER, Peter. O Melhor de Peter Druker: A Administração. São Paulo: Nobel, 2002.

GIL, Antônio C. Como elaborar projetos de pesquisa. São Paulo: Atlas, 2007.

HANSE, Don R.; MOWEN, Maryanne M. Gestão de custos contabilidade e controle. São Paulo: Pioneira Thomson Learning, 1996.

HENRIQUE, M. A. A importância da contabilidade gerencial para micro e pequena empresa. Taubaté: UNITAU, 2008. 
A IMPORTÂNCIA DA CONTABILIDADE GERENCIAL PARA O ADMNISTRADOR: estudo de caso no Escritório contábil Wbarros Consultoria Contábil

IUDÍCIBUS, S. Contabilidade gerencial. 4. ed. São Paulo: Atlas, 1986.

LEITE et al. Orçamento empresarial: levantamento da produção científica no período de 1995 à 2006. Contabilidade e Finanças, São Paulo, v. 19, mai./Ago. 2008. ISSN 47.

LIMA, Eliane S. Concepção e aplicação de sistema de informação para expectativa de resultado de desempenho estratégico. Scielo, Foz do Iguaçu-RJ, 1998. ISSN 01. Disponível em:

$<$ https://www.scielo.br/scielo.php?pid=S0103-

$65131999000100 \quad$ 005\&script=sci_arttext\&tlng=pt $>$. Acesso em: 15 maio 2021.

MARION, J. C. Contabilidade Básica. 5‥ ed. São Paulo: Atlas, 1998.

PADOVEZE. Contabilidade gerencial. Curítiba: lesde, 2012.

PADOVEZE, C. L. Contabilidade gerencial: um enfoque em sistema de informação contábil. 7. ed. São Paulo: Atlas, 2010.

ROPPELLI, A. A.; NIKBAKHT, E. Administração financeira. 2. ed. São Paulo: Saraiva, 2002. 
SCHMIDT, P.; SANTOS, J. L. D.; PINHEIRO, P. R. Introdução à contabilidade gerencial. (coleção resumos de contabilidade). São Paulo: Atlas, 2002.

SINGER, C. M.; DE CESARO, N. H. A importância dos relatórios contábeis gerenciais na tomada de decisão das organizações de determinado setor econômico de um dos municípios da região do codemau. Revista de administração, v. 2, n. 3, 2003. Disponível em: $<$ http://revistas.fw.uri.br/

index.php/revistadeadm/article/view/763>. Acesso em: 05 de maio de 2021.

SOUZA, A. A. Análise da satisfação de usuários de sistemas de informações contábeis. VI Simpósio de Gestão e Estratégia em Negócios Seropédica, Rio de Janeiro, Setembro 2008.

TUNG, N. H. Controladoria financeira das empresas. 5․ ed. São Paulo: Atlas, 1976.

WRIGHT, P. L. Administração estratégica: conceitos. 1. ed. São Paulo: Atlas, 2011. 